\title{
Compressive Strength of Compacted Clay-Sand Mixes
}

\author{
Faseel Suleman Khan, ${ }^{1}$ Shahid Azam, ${ }^{1}$ \\ Mavinakere Eshwaraiah Raghunandan, ${ }^{2}$ and Ryan Clark ${ }^{1}$ \\ ${ }^{1}$ Environmental Systems Engineering, Faculty of Engineering and Applied Science, University of Regina, 3737 Wascana Parkway, \\ Regina, SK, Canada S4S OA2 \\ ${ }^{2}$ School of Engineering, Monash University Malaysia, Jalan Lagoon Selatan, 47500 Bandar Sunway, Selangor Darul Ehsan, Malaysia
}

Correspondence should be addressed to Shahid Azam; shahid.azam@uregina.ca

Received 26 July 2014; Accepted 16 October 2014; Published 6 November 2014

Academic Editor: Bin Li

Copyright (C) 2014 Faseel Suleman Khan et al. This is an open access article distributed under the Creative Commons Attribution License, which permits unrestricted use, distribution, and reproduction in any medium, provided the original work is properly cited.

\begin{abstract}
The use of sand to improve the strength of natural clays provides a viable alternative for civil infrastructure construction involving earthwork. The main objective of this note was to investigate the compressive strength of compacted clay-sand mixes. A natural clay of high plasticity was mixed with $20 \%$ and $40 \%$ sand (SP) and their compaction and strength properties were determined. Results indicated that the investigated materials exhibited a brittle behaviour on the dry side of optimum and a ductile behaviour on the wet side of optimum. For each material, the compressive strength increased with an increase in density following a power law function. Conversely, the compressive strength increased with decreasing water content of the material following a similar function. Finally, the compressive strength decreased with an increase in sand content because of increased material heterogeneity and loss of sand grains from the sides during shearing.
\end{abstract}

\section{Introduction}

Civil infrastructure involving earthworks such as pavements, pipelines, and buildings is severely distressed in Regina, Saskatchewan, due to the expansive nature of the native soil [1]. Chemical admixtures such as lime [2] and engineering techniques such as nailing [3] have been attempted in various projects within the city. The low success rate of these methods is attributed to the harsh local climate characterized by aridity and freezing temperatures and the interaction of the active clay with the additives. The use of inert materials provides an environmentally friendly option in improving the shear strength of indigenous soils while still being cost-effective to the consumer.

The behaviour of compacted clay-sand mixes depends on the amount of constituents, compaction characteristics, and test conditions. Shafiee et al. [4] reported that the undrained shear strength increases with increasing sand content. Likewise, Vallejo and Mawby [5] demonstrated that the shear strength is governed by the granular phase when the sand content is greater than $75 \%$ and by the cohesive phase when the clay content is greater than $40 \%$. The predominance of clay matrix occurs when the clay content is more than $40 \%$ as confirmed by Wood and Kumar [6]. Likewise, Prakasha and Chandrasekaran [7] concluded that the inclusion of sand grains in a clay matrix leads to an increase in pore pressure resulting in a decrease in undrained shear strength. The research on sand-bentonite mixes concludes that the shear strength of these materials increases with decreasing water content [8], increasing dry density Blatz et al. [9], and increasing confining pressure [10].

The triaxial shear test is frequently used because of the laterally restrained soil conditions in most geotechnical applications. Consequently, comparable data on unconfined compressive strength for clay-sand mixes is sparsely reported in the literature. Nonetheless, the unconfined compression test is useful for laterally exposed conditions and applicable to fine-grained soils under undrained loading [11], requires a short testing time, is easy to conduct data analysis, and is used in the design of road embankments, shallow footings, and retaining walls.

The main objective of this note was to investigate the compressive strength of compacted clay-sand mixes. The clay 
was mixed with $20 \%$ and $40 \%$ sand and their index properties and compaction characteristics were determined. The stressstrain behaviour and the unconfined compressive strength were analyzed.

\section{Materials and Methods}

The natural clay (NC) and river sand (RS) were retrieved from local test pits in and around Regina. The materials were obtained using the ASTM Standard Practice for Soil Investigation and Sampling by Auger Borings (D1452-09) and were transported to the Geotechnical Testing Laboratory at the University of Regina as per the ASTM Standard Practice for Preserving and Transporting Soil Samples (D4220-95(07)). Clay-sand mixes were prepared based on dry weights of the materials: CS-I (80\% NC and 20\% RS) and CS-II (60\% NC and $40 \% \mathrm{RS}$ ).

The geotechnical index properties were determined for preliminary soil assessment according to standard ASTM test methods as follows: (i) specific gravity $\left(G_{s}\right)$ by the Standard Test Method for Specific Gravity of Soil Solids by Water Pycnometer (D854-10); (ii) particle-size analysis by the Standard Test Method for Particle-Size Analysis of Soils (D6913-04(2009)); (iii) liquid limit $\left(w_{L}\right)$, plastic limit $\left(w_{p}\right)$, and plasticity index $\left(I_{p}\right)$ by the Standard Test Method for Liquid Limit, Plastic Limit, and Plasticity Index of Soils (D4318-10). The clay and the sand were classified according to the Standard Practice for Classification of Soils for Engineering Purposes (Unified Soil Classification System (USCS)) (D2487-11).

The clay-sand mixes were prepared on dry mass basis and predetermined amounts of tap water were added. The samples were put in sealed plastic bags and left overnight to ensure uniform moisture distribution. Standard proctor tests were carried out as per Standard Test Method for Laboratory Compaction Characteristics of Soil Using Standard Effort (ASTM D698-12), by compacting the samples in a mould with 25 blows per layer over three layers. A $2.5 \mathrm{~kg}$ hammer was dropped from a height of $300 \mathrm{~mm}$ on to the sample layer. The water content $(w)$ was determined by the Standard Test Method for Laboratory Determination of Water (Moisture) Content of Soil and Rock by Mass (D2216-10).

The unconfined compressive strength was determined according to the ASTM Standard Test Method for Unconfined Compressive Strength of Cohesive Soil (D2166-13). The compaction specimens were extracted from the moulds using a hollow steel tube and the former were trimmed to $50 \mathrm{~mm}$ diameter and $110 \mathrm{~mm}$ height. The height-to-diameter ratio was 2.2 which was within the range (2.0 to 2.5 ) specified by ASTM. The specimen's dimensions were determined using a Vernier caliper at three different locations. Strain was applied at a rate of $0.5 \mathrm{~mm} / \mathrm{min}$ and the test was stopped when load decreased with increasing strain or until 15\% strain was reached. The data were digitally recorded and stored in a portable computer.

\section{Results and Discussions}

Table 1 gives the geotechnical index properties of the investigated materials. The specific gravity of $\mathrm{NC}$ was found
TABLE 1: Geotechnical index properties of the investigated materials.

\begin{tabular}{lccc}
\hline Property & Test method & Natural clay & River sand \\
\hline $\begin{array}{l}\text { Specific gravity }\left(G_{s}\right) \\
\text { Material finer than }\end{array}$ & D854-10 & 2.75 & 2.65 \\
$0.075 \mathrm{~mm}$ & D6913-04(09) & 98.5 & 1.0 \\
$\begin{array}{l}\text { Material finer than } \\
0.002 \mathrm{~mm}\end{array}$ & D6913-04(09) & 64.0 & - \\
$D_{10}(\mathrm{~mm})$ & $\mathrm{D} 2487-11$ & - & 0.34 \\
$D_{30}(\mathrm{~mm})$ & $\mathrm{D} 2487-11$ & - & 0.85 \\
$D_{60}(\mathrm{~mm})$ & D2487-11 & - & 1.81 \\
Coefficient of & D2487-11 & - & 1.2 \\
curvature $\left(C_{c}\right)^{\mathrm{a}}$ & & & \\
Coefficient of & D2487-11 & - & 5.3 \\
uniformity $\left(C_{u}\right)^{\mathrm{b}}$ & $\mathrm{D} 4318-10$ & 63 & - \\
Liquid limit, $w_{L}(\%)$ & D4318-10 & 28 & - \\
Plastic limit $w_{P}(\%)$ & D2487-11 & $\mathrm{CH}$ & SP \\
USCS classification & &
\end{tabular}

${ }^{\mathrm{a}} C_{c}=D_{30}{ }^{2} /\left(D_{10} \cdot D_{60}\right)$.

${ }^{\mathrm{b}} C_{u}=D_{60} / D_{10}$.

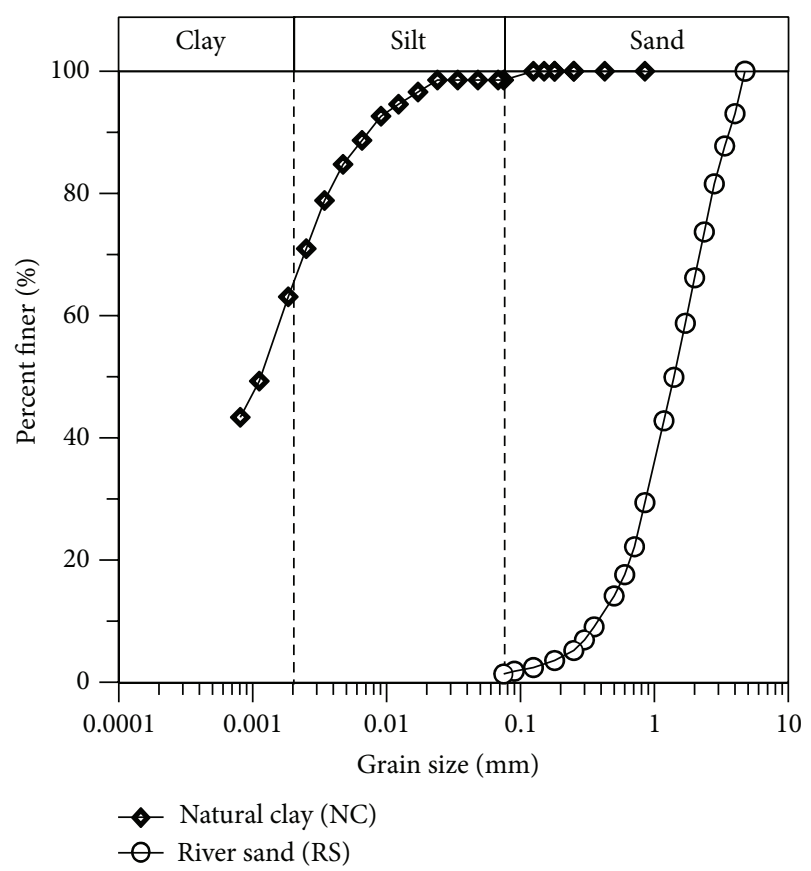

FIGURE 1: Grain size distribution of the investigated materials.

to be 2.75 which is typical of sedimentary clays (ranging between 2.4 and 2.95 [12]). The grain size distribution (Figure 1) showed 98\% material finer than $0.075 \mathrm{~mm}$ and $64 \%$ material finer than $0.002 \mathrm{~mm}$. The liquid limit was $63 \%$ and plastic limit was $28 \%$ thereby indicating a moderate water adsorption capacity. The clay was classified as high plasticity clay $(\mathrm{CH})$. In contrast, the $G_{s}$ of RS was 2.65 which is typical for materials primarily composed of quartz. About $1 \%$ of the material was found to be finer than $0.075 \mathrm{~mm}$ (Figure 1). The coefficient of curvature $\left(C_{c}\right)$ was 1.2 and the coefficient of 


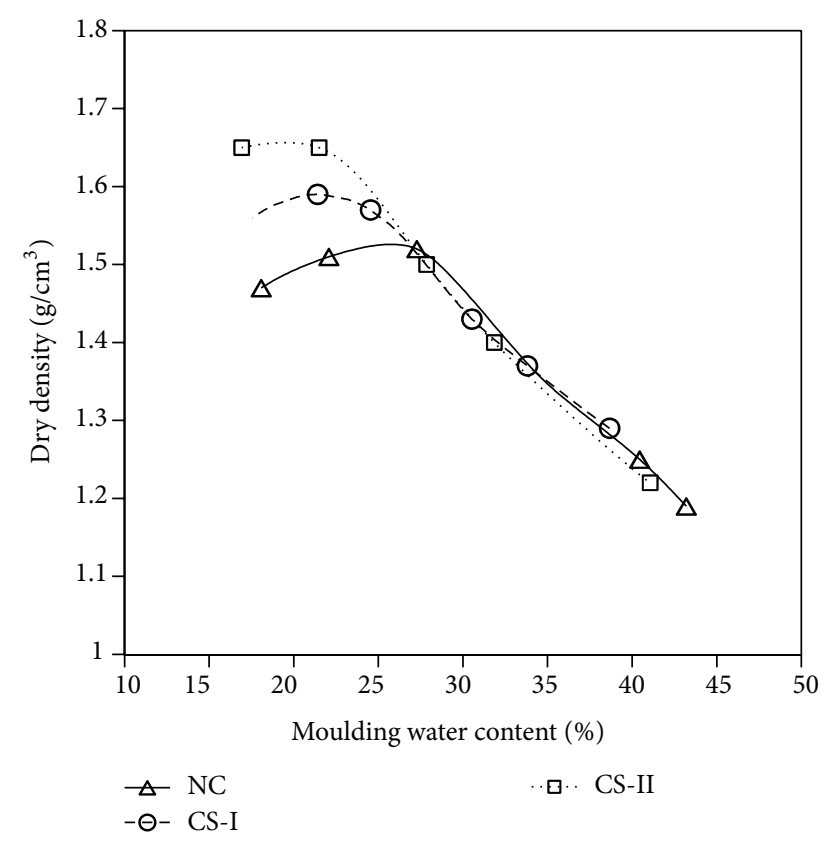

FIGURE 2: Compaction characteristics for the investigated materials.

uniformity $\left(C_{u}\right)$ was 5.3 . Overall, RS was classified as poorly graded sand (SP).

Figure 2 presents the compaction curves for the investigated materials. The NC showed a maximum dry density of $1.52 \mathrm{~g} / \mathrm{cm}^{3}$ at an optimum water content $\left(w_{\text {opt }}\right)$ of $27 \%$ which is close to the plastic limit (28\%). Marinho and Oliveira [13] reported that for cohesive soils the optimum water content is within $\pm 5 \%$ of the plastic limit. These data are similar to those reported by Azam and Chowdhury [14] for the same material. The corresponding values of dry density and optimum water content were $1.60 \mathrm{~g} / \mathrm{cm}^{3}$ at $22 \%$ for CS-I and $1.65 \mathrm{~g} / \mathrm{cm}^{3}$ at $20 \%$ for CS-II. The upward and leftward shift of the curves for increased sand content (reduced clay content) is attributed to a decreased void ratio along with a lower water requirement to lubricate the large specific surface areas of the clay particles [11]. Conversely, the decrease in the maximum dry density values with an increase in NC content is due to an increased void ratio of the clay phase and a high water demand for clay particles lubrication.

Figure 3 shows the stress-strain plots for the investigated materials. Up to the optimum water content (27\%), NC exhibited distinct peak stresses $(7900 \mathrm{kPa}, 7200 \mathrm{kPa}, 7150 \mathrm{kPa})$ at strains ranging from $2 \mathrm{~mm}$ to $5 \mathrm{~mm}$. All of these curves dropped sharply exhibiting a brittle material behaviour that was devoid of any residual strength. On the wet side of optimum, NC exhibited ductile behaviour with peak stresses of $1300 \mathrm{kPa}$ and $800 \mathrm{kPa}$ at strains ranging from $4 \mathrm{~mm}$ to $7 \mathrm{~mm}$. On the dry side of optimum, the presence of large air-filled macropeds, which are aggregates of particles, can exhibit high strength, whereas on the wet side of optimum these macropeds soften [15]. Compacted soils on the dry side of optimum have two families of pores, micropores (intraaggregate pores) and macropores (interaggregate pores), and have a continuous air phase and discontinuous water phase. On the wet side, the soil has a single family of pores: micropores, air is occluded and water phase is continuous [16]. The brittleness on the dry side of optimum is mainly due to the flocculated clay structure (aggregates of particles) making it difficult for multiparticle assemblages to slide past each other and also due to the relatively low amount of water (discontinuous water phase) available for lubrication. However, the ductile behavior on the wet side of optimum is due to a dispersed clay structure (single particles or particle groups acting independently [17]) and also due to more lubrication offered from the continuous water phase making it easy for individual particles to slide past each other thereby generating strain before failure.

Samples CS-I and CS-II also exhibited a brittle response up to the dry side of optimum and a ductile response on the wet side of optimum. This was attributed to the dominance of clay fraction ( $>40 \%$ in CS-I and CS-II) over the sand fraction resulting in a similar behaviour to $\mathrm{NC}$ but with reduced peak stresses due to a reduced clay content. The peak stress and strain for CS-I were $5600 \mathrm{kPa}$ and $3.7 \mathrm{~mm}$ in the former case. The corresponding values on the wet side of optimum were found to range from $2000 \mathrm{kPa}$ to $300 \mathrm{kPa}$ at strains ranging from $7 \mathrm{~mm}$ to $8 \mathrm{~mm}$. Likewise, the peak stress and strain for CS-II on the dry side of optimum were $4500 \mathrm{kPa}$ and $3 \mathrm{~mm}$. The corresponding values on the wet side of optimum were found to range from $2600 \mathrm{kPa}$ to $50 \mathrm{kPa}$ at strains ranging from $2 \mathrm{~mm}$ to $8 \mathrm{~mm}$. Figure 3 further indicates that, at high water contents, the axial stress is virtually independent of axial strain for CS-I and CS-II samples. This is attributed to the combined effect of the following: (i) strain softening associated with particle lubrication due to a continuous water phase at high sand contents; (ii) enhanced sample heterogeneity due to increased sand content; and (iii) loss of sand grains from the sample sides during shearing that resulted in higher strains.

Figure 4 plots the compressive strength (half the peak axial stress) with respect to dry density (Figure 4(a)) and water content (Figure 4(b)). The compressive strength increased with an increase in dry density in each of the materials. NC exhibited the highest increase in compressive strength followed by CS-I and then by CS-II. The compressive strength increased from $220 \mathrm{kPa}$ at a dry density of $1.2 \mathrm{~g} / \mathrm{cm}^{3}$ to $4000 \mathrm{kPa}$ at $1.5 \mathrm{~g} / \mathrm{cm}^{3}$. The compressive strength for CS-I increased from $150 \mathrm{kPa}$ to $2800 \mathrm{kPa}$ when the dry density increased from $1.3 \mathrm{~g} / \mathrm{cm}^{3}$ to $1.6 \mathrm{~g} / \mathrm{cm}^{3}$. Similarly, CS-II exhibited an increase in compressive strength from $30 \mathrm{kPa}$ to $2200 \mathrm{kPa}$ when the dry density increased from $1.3 \mathrm{~g} / \mathrm{cm}^{3}$ to $1.6 \mathrm{~g} / \mathrm{cm}^{3}$. In contrast, increasing the water content showed a reverse trend. NC exhibited the highest increase in compressive strength with a decrease in water content followed by CS-I and then by CS-II. Overall, the data points exhibited scatter, especially for NC and CS-I for high compressive strength (dry side of optimum water content). This is mainly due to the nonuniform moisture distribution associated with the low unsaturated hydraulic conductivity of the clay as well as dead ends and high tortuosity within these samples. 

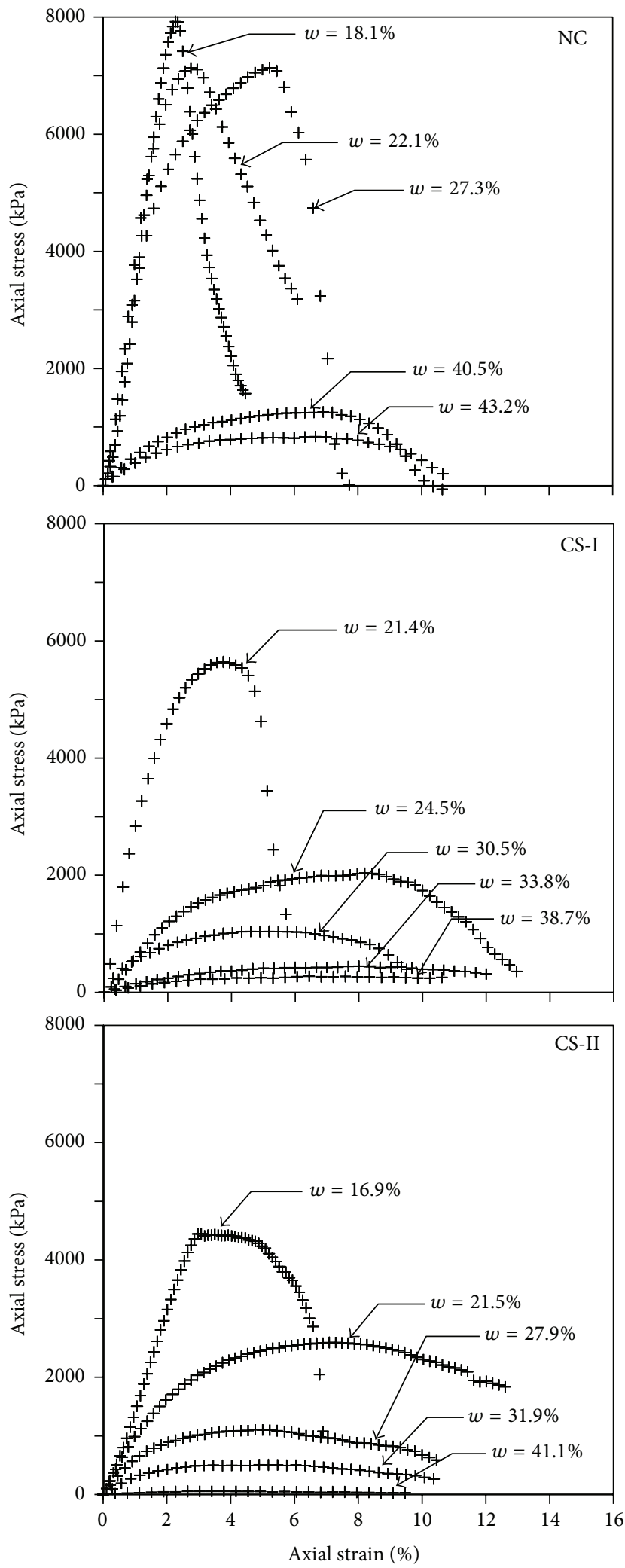

FIGURE 3: Stress-strain behaviour of the investigated materials. 


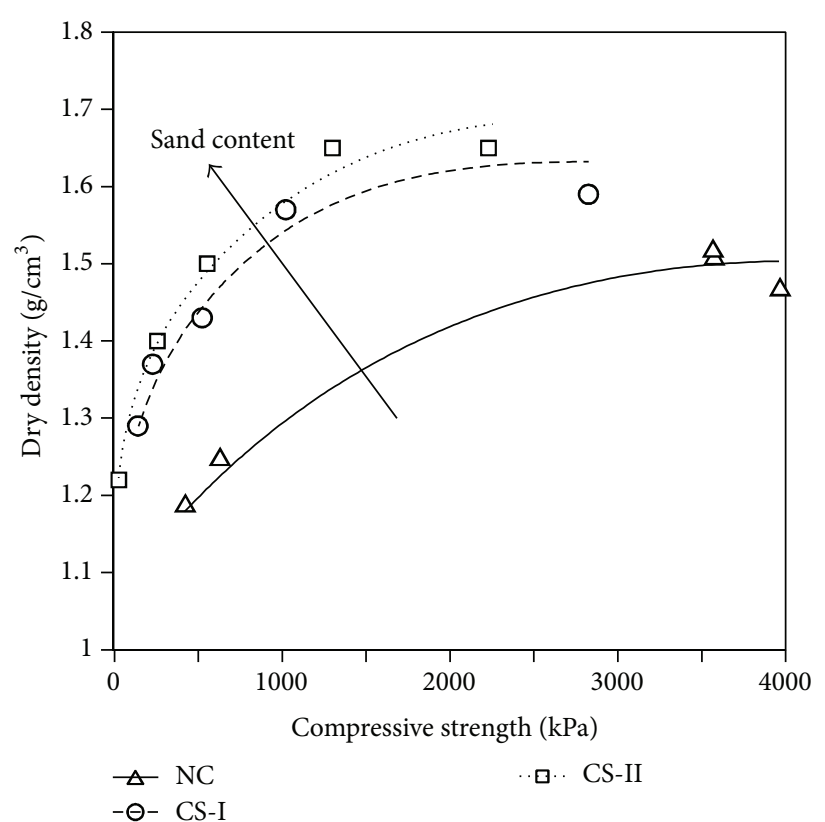

(a)

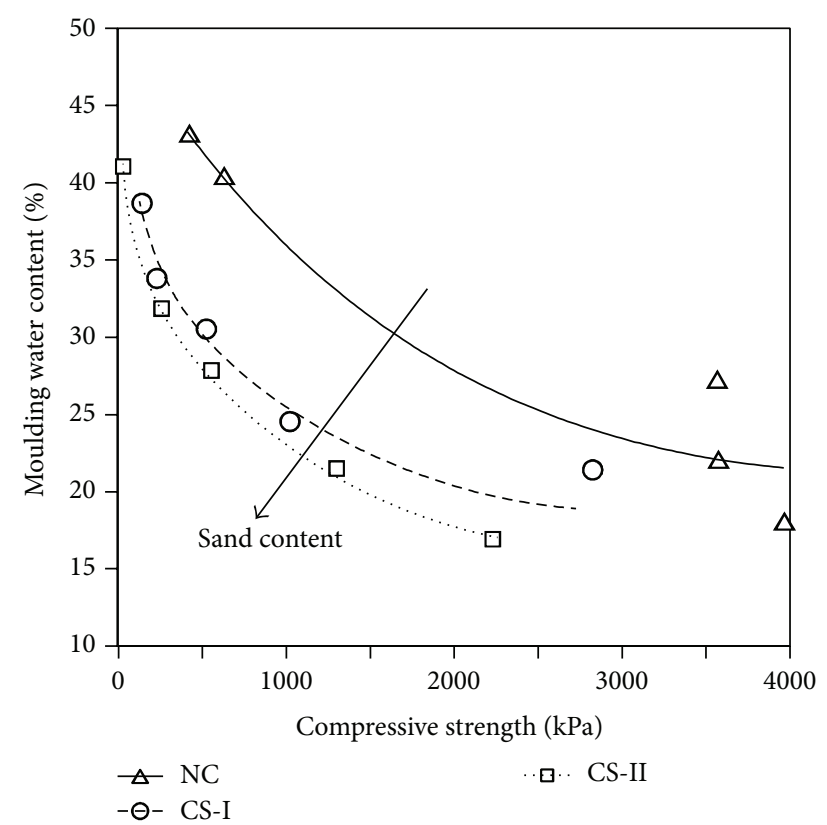

(b)

FIGURE 4: Compressive strength versus dry density and water content.

Despite the lowest maximum dry density, the clay exhibited the highest compressive strength. The higher degree of heterogeneity in the clay-sand mixes compared to the clay led to lower strength values because the failure plane had to pass through weakest zone in the sample Mullins and Panayiotopoulos [18]. Furthermore, during shearing, sand grains fell out from the sides in the test samples of clay-sand mixes. This reduced the cross sectional areas of the samples available for taking the applied load and, as such, reduced strength.

\section{Summary and Conclusions}

The unconfined compressive strength was determined for compacted samples of a natural clay of high plasticity and clay-sand mixes containing $20 \%$ and $40 \%$ sand (SP). All materials exhibited a brittle behaviour on the dry side of optimum and a ductile behaviour on the wet side of optimum. For each material, the compressive strength increased with an increase in density following a power law function. Conversely, the compressive strength increased with decreasing water content of the material following a similar function. Finally, the compressive strength decreased with an increase in sand content because of increased material heterogeneity and loss of sand grains from the sides during shearing.

\section{Conflict of Interests}

The authors declare that there is no conflict of interests regarding the publication of this paper.

\section{Acknowledgments}

The authors would like to gratefully acknowledge the Saskatchewan Ministry of Highways and Infrastructure for providing material support. Special thanks are due to the University of Regina for providing laboratory space.

\section{References}

[1] M. Ito, "Engineering properties of a vertisolic expansive soil deposit," Engineering Geology, vol. 152, pp. 10-16, 2013.

[2] D. A. Sweeney, D. K. H. Wong, and D. G. Fredlund, "Effect of lime on highly plastic clay with special emphasis on aging," Transportation Research Record, no. 1190, pp. 13-23, 1988.

[3] P. J. Antunes, M. D. Haug, R. S. Osicki, D. C. LePoudre, and R. A. Widger, "Application of air launched soil nails as an innovative remediation technology to a landslide on the Saskatchewan highway network," in Proceedings of the 59th Geotechnical Conference, Vancouver, Canada, 2006.

[4] A. Shafiee, H. R. Tavakoli, and M. K. Jafari, "Undrained behavior of compacted sand-clay mixtures under monotonic loading paths," Journal of Applied Sciences, vol. 8, no. 18, pp. 3108-3118, 2008.

[5] L. E. Vallejo and R. Mawby, "Porosity influence on the shear strength of granular material-clay mixtures," Engineering Geology, vol. 58, no. 2, pp. 125-136, 2000.

[6] D. M. Wood and G. V. Kumar, "Experimental observations of behaviour of heterogeneous soils," Mechanics of CohesiveFrictional Materials, vol. 5, no. 5, pp. 373-398, 2000.

[7] K. S. Prakasha and V. S. Chandrasekaran, "Behavior of marine sand-clay mixtures under static and cyclic triaxial shear," Journal of Geotechnical and Geoenvironmental Engineering, vol. 131, no. 2, pp. 213-222, 2005.

[8] G. X. Tang, J. Graham, J. Blatz, M. Gray, and R. K. N. D. Rajapakse, "Suctions, stresses and strengths in unsaturated sand-bentonite," Engineering Geology, vol. 64, no. 2-3, pp. 147156, 2002.

[9] J. A. Blatz, J. Graham, and N. A. Chandler, "Influence of suction on the strength and stiffness of compacted sand-bentonite," 
Canadian Geotechnical Journal, vol. 39, no. 5, pp. 1005-1015, 2002.

[10] B. Wiebe, J. Graham, G. X. Tang, and D. Dixon, "Influence of pressure, saturation, and temperature on the behaviour of unsaturated sand-bentonite," Canadian Geotechnical Journal, vol. 35, no. 2, pp. 194-205, 1998.

[11] R. D. Holtz, W. D. Kovacs, and T. C. Sheahan, An Introduction to Geotechnical Engineering, Prentice Hall, Englewood Cliffs, NJ, USA, 2011.

[12] K. Terzaghi, R. B. Peck, and G. Mesri, Soil Mechanics in Engineering Practice, John Wiley \& Sons, New York, NY, USA, 1996.

[13] F. A. M. Marinho and O. M. Oliveira, "Unconfined shear strength of compacted unsaturated plastic soils," Proceedings of the Institution of Civil Engineers: Geotechnical Engineering, vol. 165, no. 2, pp. 97-106, 2012.

[14] S. Azam and R. H. Chowdhury, "Swell-shrink-consolidation behaviour of compacted expansive clays," International Journal of Geotechnical Engineering, vol. 7, no. 4, pp. 424-430, 2013.

[15] L. Barden and G. R. Sides, "Engineering behavior and structure of compacted clay," Journal of Soil Mechanics Foundation Division, vol. 96, no. 4, pp. 1171-1200, 1970.

[16] S. Leroueil and D. W. Hight, "Compacted soils: from physics to hydraulic and mechanical behaviour," in Proceedings of the 1st Pan-American Conference on Unsaturated Soils (PanAmUNSAT '13), pp. 41-59, Cartagena, Colombia, February 2013.

[17] J. K. Mitchell and K. Soga, Fundamentals of Soil Behaviour, John Wiley \& Sons, New York, NY, USA, 3rd edition, 2005.

[18] C. E. Mullins and K. P. Panayiotopoulos, "The strength of unsaturated mixtures of sand and kaolin and the concept of effective stress," Journal of Soil Science, vol. 35, no. 3, pp. 459$468,1984$. 

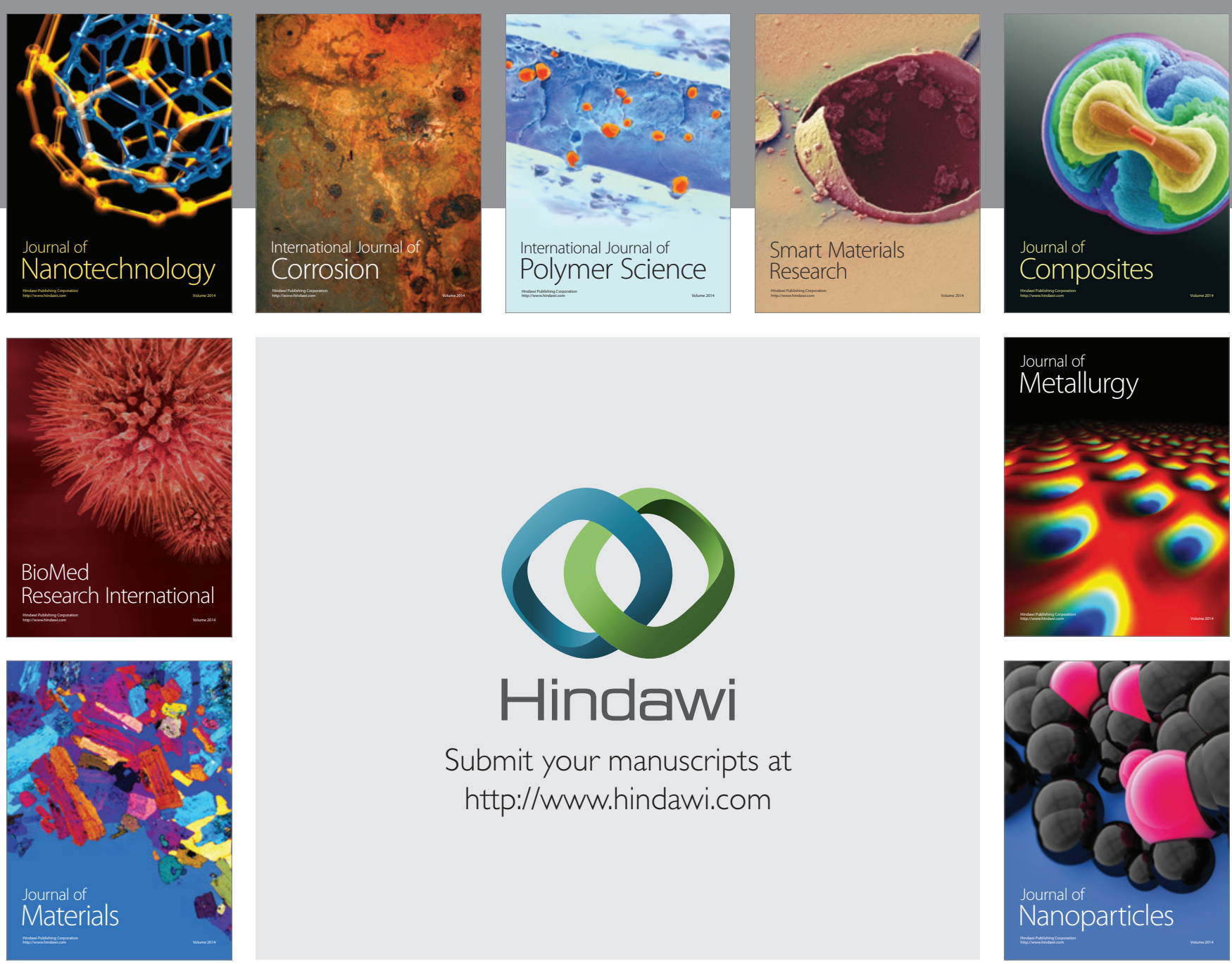

Submit your manuscripts at http://www.hindawi.com
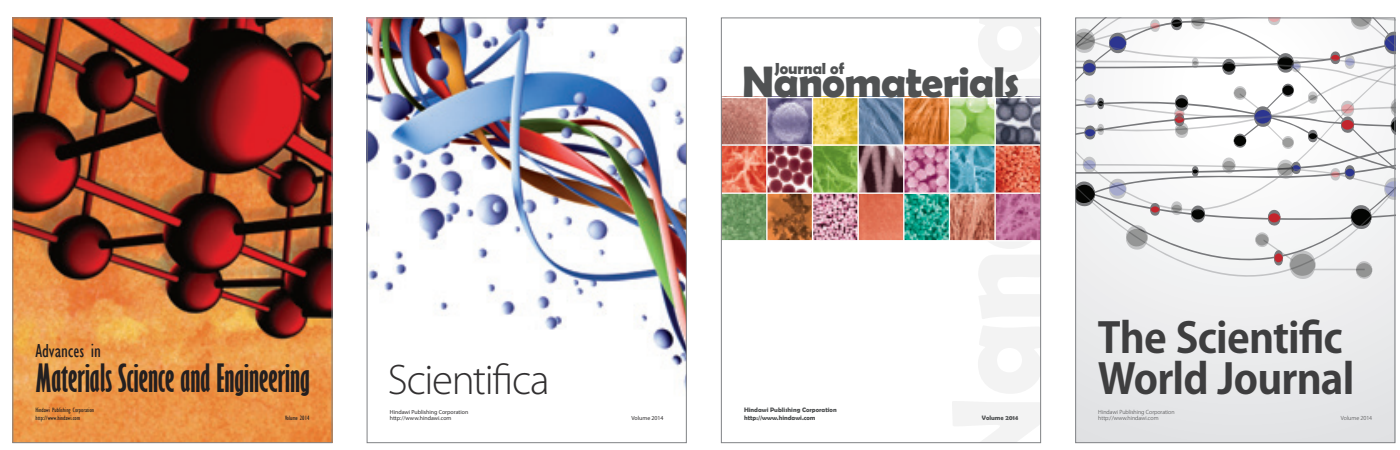

\section{The Scientific World Journal}
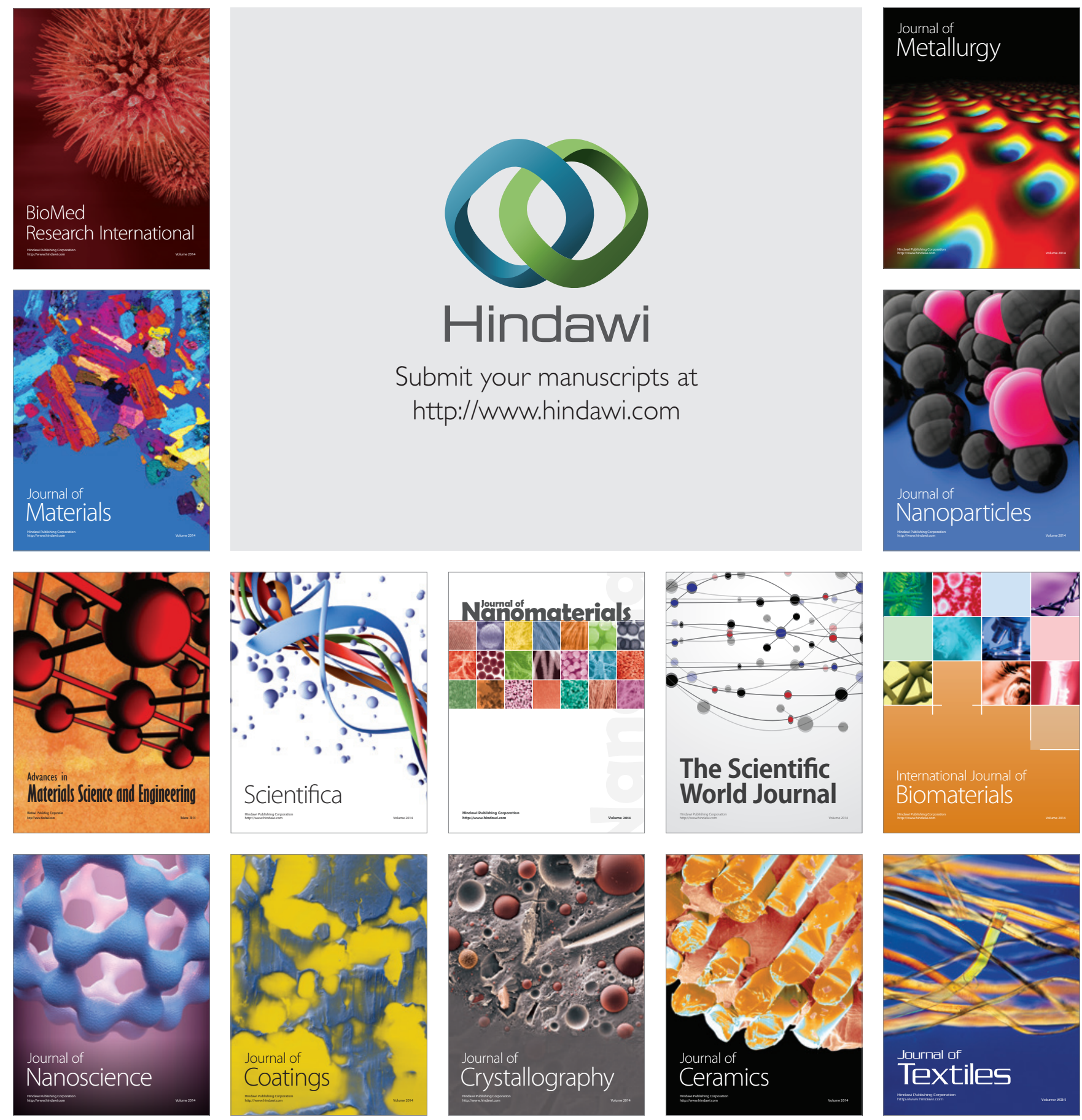